\title{
Comissões de ética dos jornalistas: atuação, visibilidade e efetividade
}

\section{Rogério Christofoletti}

\section{Resumo}

Jornalistas contam com alguns instrumentos de acompanhamento e fiscalização deontológica, sendo os mais conhecidos os códigos de ética. Para fazer cumpri-los, existem comissões ou conselhos de ética, vinculados a entidades de classe. Este artigo avalia essas instâncias nos 31 sindicatos filiados à Federação Nacional dos Jornalistas (Fenaj), levando-se em conta a frequência de sua atuação, visibilidade junto à corporação, e suas condições de atuação. Para tanto, recorremos a análises das seções correspondentes das comissões nos sites dos sindicatos e a questionários respondidos por seus membros. 0s resultados permitem identificar pouca visibilidade pública das comissões, dificuldades internas, culturais e estruturais, e uma tímida atuação no âmbito da categoria.

\section{Palavras-Chave}

Sistema deontológico. Ética jornalística.

Conduta profissional.

\section{Rogério Christofoletti}

I rogerio.christofoletti@uol.com.br

Doutor em Ciências da Comunicação. Professor do Departamento e do Programa de Pós-Graduação em Jornalismo da Universidade Federal de Santa Catarina - UFSC. Pesquisador de produtividade do CNPq e um dos líderes do Observatório da Ética Jornalística.
No final de junho de 2015, uma manifestação do Conselho de Ética do Sindicato dos Jornalistas do Paraná causou espécie. A nota publicada no site da entidade ${ }^{2}$ dava conta de uma decisão sobre denúncia contra uma jornalista acusada de violações ao Código de Ética profissional. No comunicado, o sindicato informava ter acatado a sentença do conselho de penalizar a jornalista pela comprovação de plágio, impedindo-a de ingressar em seu quadro de associados. $O$ episódio causou rumores diversos na categoria pela decisão em si - uma condenação pública! - e pela raridade com que notícias como aquela circulam.

0 processo foi iniciado em agosto de 2014, motivado pela denúncia de 42 profissionais de quatro veículos diferentes que acusavam Joice Hasselmann de plagiar textos de outros colegas integral ou parcialmente. No parecer final $^{3}$, a comissão afirma que acatou a denúncia e iniciou um trâmite sigiloso de investigação, dada a consistência das provas apresentadas: 65 reportagens teriam sido plagiadas. A comissão relata que tentou ouvir a acusada em diversas ocasiões, mas esta não apresentou 
sua defesa nem compareceu ao sindicato nas datas das convocações. Foi considerada revel e julgada, conforme especificam o Código de Ética do Jornalista Brasileiro e a Resolução 01/2009, do Conselho Nacional de Ética da Fenaj. A comissão comprovou o teor das denúncias e decidiu adverti-la publicamente por apropriação e contrafação. A jornalista também foi impedida de se filiar ao sindicato.

Imediatamente após o anúncio da decisão, a jornalista Joice Hasselmann respondeu à condenação em seu perfil no Facebook ${ }^{4}$, questionando a legitimidade e validade do processo, chamando o sindicato de "escória do jornalismo", de "invejosos, arrogantes e incompetentes". Diante da sanção, desdenhou: "Sou pessoa jurídica, dona do meu nariz, não pago pedágio para essa corja e não me dobro a essa gentinha ligada à CUT. Eu NÃ0 sou filiada ao sindicato porque eu nunca quis. Querer me punir me impedindo de integrar esse sindicato é elogio". Ao final, sinalizou ações judiciais contra os responsáveis ("enfrentem meus advogados seus sanguessugas").

0 descaso de Joice Hasselmann diante da decisão não evidencia apenas a indignação de quem não concorda com uma sentença desfavorável.
Demonstra também a extrema fragilidade do sistema deontológico dos jornalistas no Brasil, dado o limitado alcance das sanções previstas no código de ética da categoria. De acordo com 0 artigo 17, jornalistas que descumprem o documento estão sujeitos às penalidades de "observação, advertência, suspensão e exclusão do quadro social do sindicato e à publicação da decisão da comissão de ética em veículo de ampla circulação". Para jornalistas não sindicalizados, as sanções restringemse a "observação, advertência, impedimento temporário e impedimento definitivo de ingresso no quadro social do sindicato e à publicação da decisão da comissão de ética em veículo de ampla circulação". Note-se que não há possibilidade de cassação de registro profissional ou outras formas de impedimento do exercício jornalístico.

Como a associação a entidades classistas é um ato de vontade e não limita a atuação profissional, as penalidades são frágeis, quase inócuas. Podese argumentar que os constrangimentos vindos da advertência pública em caso de condenação são fortes punições, mas a resposta de Joice Hasselmann ilustra a pouca efetividade do sistema. Depreende-se ainda que a instância 
de julgamento - a comissão de ética - não goza de reconhecimento por parte da acusada, o que apequena ainda mais sua decisão.

\section{Um sistema deontológico}

No Brasil, a ética profissional dos jornalistas encontra respaldo em alguns constructos sociais, basicamente códigos de conduta e instâncias de fiscalização do atendimento dessas normas.

0 código de ética é 0 documento mais comum para orientação de atitudes e respostas ${ }^{5}$, e ele pode ser privativo de um veículo - a exemplo do Diário do Litoral $^{6}$ ou do Correio Braziliense ${ }^{7}-$, de organização jornalística - como os Princípios Editoriais da Globo ${ }^{8}$, do Grupo Estado $0^{9}$ e do Sistema Jornal do Comércio de Comunicação $0^{10}$ - ou mesmo circunscritos a entidades de classe. No polo empresarial, as associações nacionais de jornais $\left(\mathrm{ANJ}^{11}\right)$, dos editores de revista $\left(\mathrm{Aner}^{12}\right)$ e empresas de rádio e TV (Abert $\left.{ }^{13}\right)$ instruem seus membros através de códigos. Na categoria profissional, quem tem papel de liderança é a Federação Nacional dos Jornalistas (Fenaj), que abriga 31 sindicatos em todo o país e dissemina o Código de Ética do Jornalista Brasileiro, reformulado em $2007^{14}$.

Os primeiros documentos do tipo surgiram nos Estados Unidos no começo do século 20 (MEYER, 1989; FOREMAN, 2010), e se alastraram pela Europa a partir da Escandinávia (LAITILA, 1995). Códigos de conduta ou declarações de princípios são demonstrações de que seus signatários comungam valores e têm preocupações éticas. Servem para padronizar atitudes, instruir respostas a desafios cotidianos, e dar satisfações ao público, na medida em que externam posicionamentos. Têm caráter normativo, pedagógico e de rendimento de contas (BERTRAND, 1999; CHRISTOFOLETTI, 2008). Os documentos originados no âmbito

Erbolato (1982) lista uma série de documentos análogos como o Decálogo do Repórter, o Credo do Jornalista e os Postulados Jornalísticos, por exemplo.

6 Disponível em <http://www.diarinho.com.br/guia-etica.pdf> Acessado em 12/08/2015.

Disponível em <http://noblat.oglobo.globo.com/noticias/noticia/2009/12/codigo-de-etica-do-correio-braziliense-250358.html> Acessado em 09/09/2015.

Disponível em <http://g1.globo.com/principios-editoriais-do-grupo-globo.html> Acessado em 09/06/2015.

Disponível em <http://g1.globo.com/principios-editoriais-do-grupo-globo.html> Acessado em 09/06/2015.

10 Disponível em <http://www.estadao.com.br/ext/codigoetica/codigo_de_etica_miolo.pdf> Acessado em 08/05/2015.

11 Disponível em <http://www.anj.org.br/codigo-de-etica-2/> Acessado em 02/09/2015.

12 Disponível em <http://aner.org.br/institucional/principios-eticos/> Acessado em 03/09/2015.

13 Disponível em <http://www.direitoacomunicacao.org.br/index2.php?option=com_docman\&task=doc_ view\&gid=15\&ltemid=99999999 $>$ Acessado em 04/04/2015.

14 Disponível em <http://www.fenaj.org.br/federacao/cometica/codigo_de_etica_dos_jornalistas_brasileiros.pdf> . Acessado em 10/03/2015. 
classista contam com vantagens adicionais: como são construídos coletivamente, passam por um exaustivo processo de discussão e de construção de consensos, o que reforça sua representatividade e legitimidade. Também são mais amplos e passíveis de adoção, já que não esbarram em limites, rotinas e costumes internos das empresas. 0s documentos das entidades patronais tendem a ser sucintos e genéricos - como se vê com a ANJ e Aner -, de forma a garantir maior liberdade para as organizações que 0 assinam. No exterior, essa característica se repete.

É importante lembrar que os códigos de ética são documentos sem força de lei, dependendo da assunção de seus valores pelos profissionais da área, e de suas consciências e convicções. Exemplos bem acabados de regramento de autorregulação, os códigos recomendam ações, não as impondo, como se dá com a legislação ordinária. Mas preveem julgamentos, sanções e advertências públicas. Os desafios são, portanto, interpretar e aplicar os códigos, já que existem largas faixas de descolamento entre os planos conceitual e material (CHRISTOFOLETTI, 2003).

No Brasil, o código de ética mais invocado em debates e nos ritos diários é o da Fenaj, por questões políticas, históricas e de abrangência.
Não é 0 "código dos patrões", pois foi gestado nos congressos da categoria; é um documento que remonta a uma tradição de mais de meio século de debates ${ }^{15} \mathrm{e}$ que já teve quatro versões anteriores (1949, 1968, 1987, 20076); é ainda um código encampado por 31 sindicatos em todas as regiões do país, o que lhe dá dimensões nacionais.

Assim, os sindicatos não têm códigos regionais, mas orientam os profissionais a seguirem 0 documento da federação a que estão vinculados. Conforme prevê o código, os instrumentos de acompanhamento e fiscalização deontológica são as comissões de ética dos sindicatos e a de âmbito nacional, que funciona como segunda instância de julgamento (artigo 15). Compostas por cinco membros, elas "são orgãos independentes, eleitas por voto direto, secreto e universal dos jornalistas". São escolhidas junto com as direções dos sindicatos e da Fenaj, e, por isso, têm mandatos coincidentes, embora sejam votadas em processo separado para evitar atrelamento político, objetivando alguma independência e autonomia. Orienta 0 trabalho das comissões um regimento interno, elaborado pela Comissão Nacional de Ética ${ }^{17}$, prevendo recebimento das denúncias, apuração e oitiva dos envolvidos, julgamento e sentenciamento de eventuais sanções.

15 Cronologias desses processos de discussão e deliberação estão em Sá (1999) e Christofoletti.

16 Tófoli (2008) se debruça sobre a mais recente edição do código da Fenaj, discutindo sua aplicação diante de deslizes e erros recorrentes do jornalismo nacional. Entre as principais inovações da versão e talvez a mais difícil de ser implementada está a cláusula de consciência que permite ao profissional recusar-se a fazer trabalhos que contrariem suas convicções pessoais.

17 Disponível em <http://www.fenaj.org.br/federacao/cometica/regimento_interno_cre_sindicatos.pdf> Acessado em 12/09/2015. 
A representação sindical em todas as regiões do país e seu desdobramento nas comissões de ética locais, unificadas em seus procedimentos e atendendo a um código de conduta e a uma instância superior comum, propicia a estruturação de um sistema de acompanhamento e fiscalização deontológica para o jornalismo brasileiro. É uma configuração que se vale de três aspectos importantes: representatividade, legitimidade e capilaridade. Porém, esses fatores asseguram um sistema consolidado e eficiente? Como atuam as comissões de ética? São visíveis pelos jornalistas e pelos públicos? São demandadas e acolhem denúncias? Como elas são compostas? Como funcionam? Têm infraestrutura e condições de trabalho? Para responder, recorremos a alguns procedimentos metodológicos para (1) identificar presença e visibilidade das comissões de ética nos sites dos sindicatos e (2) compreender sua natureza e funcionamento.

Para a primeira fase da pesquisa, analisamos os sites da Federação Nacional dos Jornalistas (Fenaj) e dos 31 sindicatos a ela filiados, a saber: Acre, Alagoas, Amapá, Amazonas, Bahia, Ceará, Distrito Federal, Espírito Santo, Goiás, Maranhão, Mato Grosso, Dourados (MS), Mato Grosso do Sul, Juiz de Fora (MG), Minas Gerais, Pará, Paraíba, Londrina (PR), Paraná, Pernambuco, Piauí, Rio de Janeiro (estado), Rio de Janeiro (município), Rio Grande do Norte, Rio Grande do Sul, Rondônia, Roraima, Santa Catarina, São Paulo, Sergipe e Tocantins. Para a observação, foi elaborada uma matriz apoiada em categorias que permitissem responder a oito questões: a) 0 site menciona a comissão?

Há seção específica?

b) 0 site apresenta a composição da comissão?

c) 0 site disponibiliza e-mail direto e visível?

d) 0 site apresenta outros canais de acesso?

e) 0 site traz 0 código de ética do jornalista?

f) 0 site explica como fazer denúncias de jornalistas?

g) 0 site explica como tramitam os processos?

h) 0 site traz histórico das decisões da comissão?

A visitação aos sites e coleta dos dados desta fase foram feitas da última semana de junho à primeira de julho de 2015.

A segunda fase da pesquisa consistiu em extrair informações de membros das comissões para melhor compreender suas realidades de trabalho e atuação. Para isso, foi elaborado um questionário a ser respondido por um membro de cada comissão. Com 25 questões abertas e de múltipla escolha, o instrumento de coleta foi aplicado eletronicamente a apenas um sujeito de cada comissão, de forma a evitar duplicidade de respostas. 0 formulário foi produzido no sistema de planilhas e documentos do Google e corresponde ao Apêndice A.

Para alcançar os sujeitos da pesquisa, contatamos as direções da federação e dos sindicatos, solicitando endereços eletrônicos dos membros das comissões. Das 31 unidades sindicais, 21 aquiesceram e encaminharam os dados. $\mathrm{Na}$ 
sequência, elegemos aleatoriamente um membro de cada comissão e enviamos nova mensagem apresentando a pesquisa, seus objetivos e 0 link do formulário. Esses procedimentos aconteceram em junho e julho de 2015, e das 21 comissões contatadas, 15 responderam ao questionário.

\section{Acesso e visibilidade das comissões}

A primeira fase deste estudo se deteve na identificação da presença e visibilidade das comissões de ética nos sites dos sindicatos. A primeira observação a ser feita é que nem todos os filiados à Fenaj dispõem de sites para se comunicar com suas bases e com demais grupos interessados. No período de análise - última semana de junho e primeira de julho de 2015 -, dois sindicatos estavam com sites fora do ar (Londrina e Rio Grande do Norte); dois dispunham de blogs desatualizados ou incompletos (Estado do Rio de Janeiro e Dourados), um mantinha uma página apenas no Facebook (Piauî) e outros dois não ofereciam nenhuma forma de contato (Roraima e Maranhão). Com isso, o universo de análise da primeira fase - antes estimado em 32 - foi reduzido a 25 unidades.

No que tange à presença e à visibilidade nos sites, registramos que as comissões de ética são mencionadas em dois terços dos endereços observados. Geralmente, a menção é feita em seções como "Diretoria" ou "Institucional", e seus membros meramente listados, sem as descrições de suas qualificações ou formas de contato. São raros os casos em que os sites dedicam uma seção exclusiva a essas instâncias, como acontece com Distrito Federal ${ }^{18}$, Pernambuco ${ }^{19}$, Rio Grande do $\mathrm{Sul}^{20}$ e Município do Rio de Janeiro ${ }^{21}$. Em apenas dois casos, há indicação de endereços eletrônicos para as comissões: no Distrito Federal, o e-mail é direcionado à secretaria do sindicato, mas a comissão do Município do Rio de Janeiro tem seu próprio e ele funciona, conforme pudemos atestar. Em nenhum dos 25 sites, encontramos canais alternativos de acesso para denúncias, dúvidas, críticas ou sugestões para as comissões.

0 Código de Ética do Jornalista Brasileiro está contido em todos os endereços analisados. Seja na forma de banners com links para arquivos em PDFs (originários da Fenaj), seja para páginas em HTML, e quase sempre em seções como "Legislação", "Institucional" ou "0 Sindicato".

No que concerne à visibilidade e ao acesso às comissões de ética, as maiores fragilidades dos sites estão nas completas ausências de informações sobre como oferecer denúncias, como tramitam os processos ali iniciados e que decisões há sobre

18 <http://www.sjpdf.org.br/comissoes/comissao-de-etica> Acessado em 05/09/2015.

19 <http://www.sinjope.org.br/sind-comissao-etica.php> Acessado em 10/09/2015

$20<$ <ttp://www.jornalistas-rs.org.br/index.php/2013-11-21-15-16-28/comissao-estadual-de-etica/comissao-estadual-de-etica. html $>$ Acessado em 12/09/2015

21 <http://jornalistas.org.br/index.php/comissao-de-etica-sjpmrj/> Acessado em 30/06/2015. 
os casos. Neste sentido, as lacunas contribuem para uma grande opacidade sobre 0 trabalho das comissões. Quase todos os sites deixam de explicar a jornalistas e a demais usuários como funcionam as comissões, quais são os ritos a partir de denúncias e que sanções foram determinadas pelas comissões nos últimos anos. As exceções ficam por conta do Distrito Federal (que orienta 0 usuário a mandar e-mail para a comissão), do Paraná (que disponibilizou recentemente a decisão sobre 0 caso Joice Hasselmann), do Espírito Santo e da Fenaj (os quais publicam os regimentos da comissão local e nacional) e do Município do Rio de Janeiro (que explica rapidamente 0 trâmite na comissão).

As conclusões a que chegamos nesta primeira fase da pesquisa é que há pouco investimento dos sindicatos na apresentação de suas comissões de ética. Há casos graves em que sequer existe site próprio, mas, em geral, quando há, não dedica uma seção específica para essa instância de acompanhamento deontológico, restringindo-se a publicar o código de ética e a composição da comissão. Também faltam dados mais detalhados sobre os próprios componentes, o funcionamento interno e um histórico de suas decisões. Assim, a visibilidade das comissões é débil, seu acesso, prejudicado, e a transparência de seus atos, inexistente.

\section{Atuação, resposta e efetividade das comissões}

A presença tímida e pouco funcional das comissões de ética nos sites dos sindicatos pode ser resultado, em parte, de suas condições internas. A segunda fase deste estudo visa a entrever a natureza e 0 funcionamento dessas instâncias, por meio de depoimentos colhidos entre seus membros.

Quinze sujeitos responderam ao formulário eletrônico (Apêndice A), e do ponto de vista censitário, $60 \%$ deles são membros e $40 \%$ respondem pelas presidências das comissões. Também entre os respondentes, $60 \%$ afirmaram já ter participado de comissões semelhantes anteriormente, o que demonstra algum equilíbrio no quesito experiência de acompanhamento deontológico.

Quando indagados sobre a frequência das reuniões, $46,7 \%$ dos sujeitos responderam que isso se dá "apenas quando a instância é acionada", $26,7 \%$ marcaram a opção "mensalmente", e 20\%, "semestralmente". Segundo informam, nenhuma comissão de ética tem encontros semanais e apenas 6,7\%, quinzenais. As reuniões são raras, conforme indicam as respostas da questão seguinte: "Em 2015, reuniram-se quantas vezes?". Dos quinze respondentes, apenas três afirmaram que suas comissões se reuniram mais de dez vezes neste ano. Outro dado reforça a baixa atividade: $76,9 \%$ dos sujeitos responderam que suas comissões recebem denúncias "raramente" e 23,1\% "muito raramente". A opção "frequentemente" não foi assinalada por ninguém.

Na maioria das vezes, os comissionados se sentem isolados: quase dois terços $(64,3 \%)$ 
disseram que não mantiveram contatos com comissões semelhantes, nem mesmo com a da Fenaj. Em 60\% dos casos, contam com suporte e aconselhamento dos departamentos jurídicos de seus sindicatos, mas em $53,3 \%$ não têm uma sala ou espaço para se reunir. 0 mesmo percentual diz não contar com computadores ou equipamentos para trabalhar. Na maioria das vezes, em 71,4\% dos casos, as comissões não dispõem de verbas para deslocamentos dos membros para reuniões ou visitas a locais de trabalho dos jornalistas. Apesar dessas precariedades, $78,6 \%$ dos consultados afirmam que as condições de trabalho oferecidas pelos sindicatos são "favoráveis e adequadas ao trabalho das comissões". No campo dos comentários finais, um dos sujeitos da pesquisa afirmou que "as condições oferecidas pelo sindicato não são as melhores, mas as possíveis", bastando que a comissão requisite apoio à direção sindical.

"Além de avaliar denúncias de desvios éticos, que outras atividades a comissão se ocupa?", perguntava o formulário. Aberta, a questão permitia que os respondentes listassem mais funções.

Majoritariamente, foram mencionados debates, edição de livros, eventos públicos, fóruns diversos, e palestras para universitários. São ações para encorajar discussões de aprimoramento ético profissional, o que resta à comissão, uma vez que ela "não tem poderes reais", conforme registrou um dos respondentes. A afirmação se apoia na fragilidade das sanções que 0 código prevê em casos de condenação pela comissão. Não é à toa que $60 \%$ dos participantes estão em comissões que não decidiram por punições/sanções, sinalizando brandura, ineficiência ou pouca efetividade do órgão.

Na avaliação dos participantes da pesquisa, as comissões são "muito importantes" (66,7\%) e "importantes" (33,3\%) para a apuração de desvios éticos na profissão; e "importante" (80\%), "muito importante" (13,3\%) e "pouco importante" $(6,7 \%)$ para produzir materiais de apoio a jornalistas; e "super importante" (53,2\%), "importante" (26,7\%), "pouco importante" $(13,3 \%)$ e "indiferente" (6,7\%) para liderar campanhas de difusão do código de ética.

Maior divisão foi observada sobre a importância de visitas das comissões em redações e outros locais de trabalho: 42,9\% consideram "muito importante", 28,6\%, "pouco importante"; 14,3\% disseram ser "indiferente", mesmo patamar de "importante". Tais percepções dos participantes da pesquisa apontam mais para um órgão de perfil simbólico do que de mobilização. Apesar disso, um dos sujeitos do estudo declarou que as comissões deveriam "ter uma atuação preventiva sempre que possível, não esperando que um acontecimento exatamente paute as ações desse grupo de trabalho".

\section{A composição das comissões é prevista no} regimento interno, mas um dos respondentes manifestou preocupação sobre a suficiência de cinco membros. Outro registrou que "a presença de membros indicados por outros grupos profissionais garante um julgamento imparcial, principalmente quando a queixa envolve pessoas não pertencentes 
aos quadros jornalísticos". Em 80\% dos casos, as comissões não contam com membros da sociedade, conforme informaram os participantes.

A pesquisa permitiu a emergência de problemas internos nas comissões, como o fato de que não documentam ou mantêm arquivo com os processos que analisam, admitido por 13,3\% dos respondentes. Pouco mais de um quinto $(21,4 \%)$ reconhece que a categoria não tem acesso às comissões, e outros $60 \%$ afirmam que não são órgãos conhecidos pela categoria. Um último contraste permite enxergar a imagem aparentemente contraditória das comissões no imaginário de seus componentes: para 93,3\%, elas são "importantes" ou "muito importantes" para fixar padrões éticos entre os jornalistas, mas, segundo 66,7\%, não são referências para suas consultas. A relevância não se traduz em reconhecimento prático e efetivo.

\section{Considerações finais}

Este artigo não apresenta resultados que apontem para uma construção histórica do sistema deontológico brasileiro, a exemplo do que apresenta Camponez (2011) para os portugueses $^{22}$. Nem tampouco, rastreia os principais dilemas e vetores da profissão (cf. MACIÁ-BARBER y DAMAS, 2010) ou coteja percepções de jornalistas e seus públicos, a exemplo do que fizeram os espanhóis Alsius y

Salgado $(2010)^{23}$.

Os objetivos do estudo estão restritos a apresentar um conjunto de informações que permita compreender melhor como as comissões de ética dos jornalistas são apresentadas pelos sindicatos e pela Fenaj, como se estruturam e que demandas respondem. Entendendo que esses órgãos são estratégicos na estrutura de um sistema deontológico no campo - pois teriam a função de acompanhar a categoria e fiscalizar a aplicação do código de conduta -, lançamos um olhar para suas vitrines e composições. A combinação de técnicas de pesquisa possibilitou que enfocássemos sete dimensões complementares: presença, visibilidade e acesso, natureza, funcionamento, limitações e funções.

Os dados colhidos na primeira etapa da pesquisa nos levam a concluir que, de forma generalizada, as unidades sindicais apresentam suas comissões para atender a uma formalidade. Em poucos casos, os órgãos têm seções específicas nos sites, e não há dados de seu funcionamento ou estrutura, sendo apresentada apenas a lista de seus componentes. Essas características tornam precária a visibilidade das comissões nessas vitrines, fragilidade que é reforçada pelas dificuldades de se entrar em contato com tais país, tendo como instrumento principal para tal discussão o Conselho Deontológico e seu entorno de autorregulação.

23 Em uma iniciativa pouco usual, Alsius e Salgado (2010) organizaram uma coletânea que contrasta as opiniões de profissionais e públicos sobre a ética em quatro regiões da Espanha. Em contexto um pouco mais restrito, Maciá-Barber e Damas (2010) apresentam os principais dilemas ético-profissionais dos jornalistas madrilenhos. 
instâncias. Em apenas um caso, foi oferecido endereço eletrônico dedicado à comissão. Em nenhum caso, canais de comunicação alternativos - como redes sociais ou telefones - foram externados ao visitante do site. Neste sentido, as condições de presença das comissões nos sites não garantem suas visibilidades e facilidades de acesso, fato que é agravado pela inexistência de um histórico de sua atuação e decisões.

Pouco visível, com acesso prejudicado e não transparente, um órgão como este - geralmente, acionado quando há litígio na área ou deslizes éticos - não atrai denúncias de membros da categoria ou mesmo de populares. Se a comissão enseja ser uma instância de fixação de boas práticas jornalísticas e difusora de balizas de conduta, precisa alcançar mais evidência no universo profissional.

A segunda parte da pesquisa colheu dados dos membros das comissões que evidenciaram diversas precariedades em seu funcionamento: pouca estrutura, raras consultas e dificuldades na implementação de ações. Ao mesmo tempo em que os membros reconhecem a importância das comissões, reconhecem também que são pouco conhecidas e pouco demandadas pela categoria. Isto é: esses órgãos não alcançam o reconhecimento almejado - e apontado nas normativas dos sindicatos e da Fenaj -, porque suas autoridades são enfraquecidas pelo limitado poder de sanção previsto no documento que as sustenta, 0 código de ética, e pelo espaço acanhado que ocupam no pretendido sistema deontológico.
0 círculo vicioso apresentado pode ser rompido caso haja investimentos efetivos para 0 empoderamento das comissões de ética, dandolhes maior visibilidade nas rotinas dos sindicatos, facilitando 0 acesso dos profissionais a esses órgãos e atribuindo-lhes funções para além das de um tribunal ético, estendendo a ações pedagógicas, de orientação e de discussão de questões deontológicas com a sociedade interessada. 0s investimentos, portanto, não são meramente financeiros - capazes de dotar de estrutura as comissões -, mas, sobretudo, políticos, na medida em que federação e sindicatos elegem a consolidação de um efetivo sistema deontológico como uma prioridade na esteira da afirmação do jornalismo como profissão, campo de saber e de construção de narrativas de nossa realidade.

\section{Referências}

ALSIUS, Salvador; SALGADO, Francesc (eds.) La ética informativa vista por los ciudadanos. Barcelona: Editorial UOC, 2010.

BERTRAND, Claude-Jean. A deontologia das mídias. Bauru: Edusc, 1999

CAMPONEZ, Carlos. Deontologia do Jornalismo. Coimbra: Almedina, 2011.

CHRISTOFOLETTI, Rogério. A preocupação com a ética: tradição e futuro. IN: BALDESSAR, Maria José; CHRISTOFOLETTI, Rogério. Jornalismo em Perspectiva. Florianópolis: Insular, 2005. . Ética no Jornalismo. São Paulo: Contexto, 2008.

Monitores de Mídia: como 0 jornalismo catarinense percebe seus deslizes éticos. 
Florianópolis-Itajaí: Ed. UFSC e Ed. Univali, 2003.

. Por um sistema deontológico

no jornalismo. Observatório da Imprensa, $\mathrm{n}^{0}$

634, 22 de março de 2011. Disponível em < http://

observatoriodaimprensa.com.br/jornal-de-debates/por-

um-sistema-deontologico-no-jornalismo > Acessado em

9 de agosto de 2015.

ERBOLATO, Mario. Deontologia da Comunicação

Social. Petrópolis: Vozes, 1982

FEDERAÇÃO NACIONAL DOS JORNALISTAS. Código

de Ética do Jornalista Brasileiro. Vitória, 2007.

FOREMAN, Gene. The ethical journalist. London:

Wiley-Blackwell, 2010

LAITILA, Tiina. Journalistic Codes of Ethics in

Europe. European Journal of Communication. Vol.

10 (4), 1995, pp.: 527-544.

MACIÁ-BARBER, Carlos; DAMAS, Susana Herrera.

La excelencia informativa: dilemas éticos y retos profesionales del periodista. Cuadernos de Periodistas, $\mathrm{n}^{0} 19$, marzo de 2010, pp. 66-95.

MEYER. Philip. A ética no jornalismo. Rio de Janeiro: Forense-Universitária, 1989.

SÁ, Adísia. 0 jornalista brasileiro: Federação Nacional dos Jornalistas, de 1946 a 1999. $2^{\text {a }}$ edição revisada, ampliada e atualizada. Fortaleza: Edições Fundação Demócrito Rocha, 1999.

TÓFOLI, Luciene. Ética no Jornalismo. Petrópolis: Vozes, 2008. 
APÊNDICE A: Questionário para Membros de Comissão de Ética

As questões abaixo fazem parte de uma pesquisa sobre as comissões de ética dos sindicatos dos jornalistas no Brasil, coordenada pelo professor Rogério Christofoletti, da Universidade Federal de Santa Catarina. 0 objetivo é detalhar a natureza e o funcionamento desses órgãos no sistema deontológico nacional.

As questões são endereçadas a membros dessas comissões, e estimamos que sejam necessários oito minutos para responder ao questionário na íntegra. 0s dados colhidos neste instrumento serão usados apenas para fins científicos. A participação da pesquisa é voluntária e é garantido o anonimato dos respondentes. Caso haja dúvidas ou sugestões, contatar o pesquisador responsável por e-mail.

Muito obrigado!

1. Qual a sua função na comissão?
( ) Membro
( ) Presidente
( ) Suplente

2. Já participou de comissão semelhante anteriormente?
( ) Sim
( ) Não

3. A comissão de ética se reúne com qual frequência?
( ) Semanalmente
( ) Quinzenalmente
( ) Mensalmente
( ) Semestralmente
( ) Apenas quando demandada

4. Em 2015, reuniram-se quantas vezes?

5. Com que frequência a comissão recebe denúncias?
( ) Raramente
( ) Frequentemente
( ) Muito raramente

6. A sua comissão de ética tem contato com outras comissões de ética jornalística?
( ) Sim
( ) Não

7. A sua comissão de ética já teve contato com a comissão nacional da Fenaj?

( ) Sim ( ) Não

8. Sua comissão tem suporte e aconselhamento do Departamento Jurídico do seu sindicato?
( ) Sim
( ) Não

9. A comissão de ética da qual faz parte tem membros da sociedade civil?
( ) Sim
( ) Não

10. A presença de membros não-jornalistas na comissão de ética é positiva?
( ) Sim
( ) Não
( ) Não se aplica, já que a comissão só tem jornalistas.

11. A comissão tem uma sala ou espaço no sindicato para se reunir e trabalhar?
( ) Sim
( ) Não

12. A comissão tem infraestrutura para funcionar, como computadores e outros equipamentos?
( ) Sim
( ) Não 
13. A comissão tem verbas para deslocamento dos seus membros para reuniões ou visitas a locais de trabalho dos jornalistas em outras cidades?
( ) Sim
( ) Não

14. As condições de trabalho oferecidas pelo sindicato são favoráveis e adequadas ao trabalho da comissão?
( ) Sim
( ) Não

15. Além de avaliar denúncias de desvios éticos, que outras atividades a comissão faz?

Escreva:

16. Considerando sua comissão de ética, assinale o grau de importância para a seguinte função: > Apurar casos de desvios éticos de jornalistas
( ) Desimportante
( ) Pouco Importante
( ) Importante
( ) Indiferente
( ) Muito importante

17. Considerando sua comissão de ética, assinale o grau de importância para a seguinte função: >> Produzir materiais para divulgação dos jornalistas
( ) Desimportante
( ) Pouco Importante
( ) Importante
( ) Indiferente
( ) Muito importante

18. Considerando sua comissão de ética, assinale o grau de importância para a seguinte função: > Liderar campanhas de difusão do código de ética da profissão
( ) Desimportante
( ) Pouco Importante
( ) Importante
( ) Indiferente
( ) Muito importante

19. Considerando sua comissão de ética, assinale o grau de importância para a seguinte função: >> Visitar as redações e assessorias de imprensa para instruir e dialogar com os colegas
( ) Desimportante
( ) Pouco Importante
( ) Importante
( ) Indiferente
( ) Muito importante

20. A comissão de ética da qual você faz parte já decidiu por punições ou sanções?
( ) Sim
( ) Não

21. A comissão de ética documenta e mantém um arquivo com os processos que analisa?
( ) Sim
( ) Não

22. Você considera que os jornalistas têm acesso à comissão de ética?
( ) Sim
( ) Não

23. Você considera que a comissão de ética é um órgão conhecido pelos jornalistas?
( ) Sim
( ) Não

24. A comissão é uma referência para consultas dos jornalistas?
( ) Sim
( ) Não

25. Você considera a comissão de ética...

( ) Importante para o estabelecimento de padrões de conduta para os jornalistas

( ) Muito importante para fixar padrões de conduta para os jornalistas

( ) Desimportante para o estabelecimento de padrões éticos para os jornalistas

( ) Pouco importante para fixar padrões de conduta para os jornalistas

Caso algum aspecto referente à comissão de ética não tenha sido tratado aqui e você queira abordá-lo, use o campo a seguir para mais comentários: 


\begin{tabular}{|c|c|}
\hline $\begin{array}{l}\text { Ethics committees of journalists: } \\
\text { acting, visibility and effectiveness }\end{array}$ & $\begin{array}{l}\text { Los comités de ética de los periodistas: } \\
\text { la actuación, la visibilidad y la eficácia }\end{array}$ \\
\hline $\begin{array}{l}\text { Abstract } \\
\text { Journalists have some monitoring tools and ethical } \\
\text { oversight, and the best known are the codes of } \\
\text { ethics. Ethics committees, linked to unions, have the } \\
\text { responsibility to ensure compliance with the ethics } \\
\text { rules. This article evaluates these commissions in } \\
31 \text { unions affiliated to the National Federation of } \\
\text { Journalists (Fenaj), considering the frequency of its } \\
\text { operations, visibility in the category and its operating } \\
\text { conditions. For that, we turn to analysis of the } \\
\text { websites of the trade unions and the questionnaires } \\
\text { answered by members of ethics committees. The } \\
\text { results identify little public visibility of commissions, } \\
\text { cultural and structural difficulties, and a timid } \\
\text { performance within the category. } \\
\text { Keywords } \\
\text { Ethical system. Journalistic ethics. } \\
\text { Professional conduct. }\end{array}$ & $\begin{array}{l}\text { Resumen } \\
\text { Los periodistas tienen algunas herramientas de } \\
\text { monitoreo y supervisión ética, como los códigos de } \\
\text { ética. Para cumplir con ellos, existen consejos de ética, } \\
\text { vinculados a las asociaciones profesionales. En este } \\
\text { artículo se evalúa los casos de } 31 \text { sindicatos afiliados } \\
\text { a la Federación Nacional de Periodistas (Fenaj), } \\
\text { teniendo en cuenta la frecuencia de sus operaciones, } \\
\text { la visibilidad en la sociedad, y sus condiciones de } \\
\text { ejecución. Para ello, recurrimos al análisis de las } \\
\text { secciones pertinentes de los consejos en los sitios web } \\
\text { de los sindicatos y de los cuestionarios respondidos } \\
\text { por sus miembros. Los resultados identifican poca } \\
\text { visibilidad pública de los consejos, las dificultades } \\
\text { internas, culturales y estructurales, y una actuación } \\
\text { tímida dentro de la categoría. } \\
\text { Palabras clave } \\
\text { Sistema ético. Ética periodística. } \\
\text { Conducta profesional. }\end{array}$ \\
\hline
\end{tabular}




\section{Expediente}

A revista E-Compós é a publicação científica em formato eletrônico da Associação Nacional dos Programas de Pós-Graduação em Comunicação (Compós). Lançada em 2004, tem como principal finalidade difundir a produção acadêmica de pesquisadores da área de Comunicação, inseridos em instituições do Brasil e do exterior.

\section{E-COMPÓS I www.e-compos.org.br I E-ISSN 1808-2599}

Revista da Associação Nacional dos Programas de Pós-Graduação em Comunicação.

Brasília, v.18, n.3, set./dez. 2015.

A identificação das edições, a partir de 2008, passa a ser volume anual com três números.

Indexada por Latindex I www.latindex.unam.mx

\section{CONSELHO EDITORIAL}

Alexandre Farbiarz, Universidade Federal Fluminense, Brasil Alexandre Rocha da Silva, Universidade Federal do Rio Grande do Sul, Brasil Ana Carolina Damboriarena Escosteguy, Pontifícia Universidade Católica do Rio Grande do Sul, Brasil

Ana Carolina Rocha Pessôa Temer, Universidade Federal de Goiás, Brasil Ana Regina Barros Rego Leal, Universidade Federal do Piauí, Brasil Andrea França, Pontifícia Universidade Católica do Rio de Janeiro, Brasil André Luiz Martins Lemos, Universidade Federal da Bahia, Brasil Antonio Carlos Hohlfeldt, Pontifícia Universidade Católica do Rio Grande do Sul, Brasil

Arthur Ituassu, Pontifícia Universidade Católica do Rio de Janeiro, Brasil Álvaro Larangeira, Universidade Tuiuti do Paraná, Brasil Ângela Freire Prysthon, Universidade Federal de Pernambuco, Brasil César Geraldo Guimarães, Universidade Federal de Minas Gerais, Brasil Cláudio Novaes Pinto Coelho, Faculdade Cásper Líbero, Brasil Daisi Irmgard Vogel, Universidade Federal de Santa Catarina, Brasil Denize Correa Araujo, Universidade Tuiuti do Paraná, Brasil Eduardo Antonio de Jesus, Pontifícia Universidade Católica de Minas Gerais, Brasil

Daniela Zanetti, Universidade Federal do Espirito Santo, Brasil Eduardo Vicente, Universidade de São Paulo, Brasil Elizabeth Moraes Gonçalves, Universidade Metodista de São Paulo, Brasil Erick Felinto de Oliveira, Universidade do Estado do Rio de Janeiro, Brasil Francisco Elinaldo Teixeira, Universidade Estadual de Campinas, Brasil Francisco Paulo Jamil Almeida Marques, Universidade Federal do Paraná, Brasil

Gabriela Reinaldo, Universidade Federal do Ceará, Brasil Goiamérico Felício Carneiro Santos, Universidade Federal de Goiás, Brasil Gustavo Daudt Fischer, Universidade do Vale do Rio dos Sinos, Brasil Herom Vargas, Universidade Municipal de São Caetano do Sul, Brasil Itania Maria Mota Gomes, Universidade Federal da Bahia, Brasil
Janice Caiafa, Universidade Federal do Rio de Janeiro, Brasil Jiani Adriana Bonin, Universidade do Vale do Rio dos Sinos, Brasil José Afonso da Silva Junior, Universidade Federal de Pernambuco, Brasil José Luiz Aidar Prado, Pontifícia Universidade Católica de São Paulo, Brasil Juçara Gorski Brittes, Universidade Federal de Ouro Preto, Brasil Kati Caetano, Universidade Tuiuti do Paraná, Brasil

Lilian Cristina Monteiro França, Universidade Federal de Sergipe, Brasil Liziane Soares Guazina, Universidade de Brasília, Brasil Luíza Mônica Assis da Silva, Universidade de Caxias do Sul, Brasil Luciana Miranda Costa, Universidade Federal do Pará, Brasil Malena Segura Contrera, Universidade Paulista, Brasil Maria Ogécia Drigo, Universidade de Sorocaba, Brasil Maria Ataide Malcher, Universidade Federal do Pará, Brasil Marcia Tondato, Escola Superior de Propaganda e Marketing, Brasil Marcel Vieira Barreto Silva, Universidade Federal da Paraíba, Brasil Maria Clotilde Perez Rodrigues, Universidade de São Paulo, Brasil Maria das Graças Pinto Coelho, Universidade Federal do Rio Grande do Norte, Brasil

Mauricio Ribeiro da Silva, Universidade Paulista, Brasil

Mauro de Souza Ventura, Universidade Estadual Paulista, Brasil Márcio Souza Gonçalves, Universidade do Estado do Rio de Janeiro, Brasil Micael Maiolino Herschmann, Universidade Federal do Rio de Janeiro, Brasil Mirna Feitoza Pereira, Universidade Federal do Amazonas, Brasil Nísia Martins Rosario, Universidade Federal do Rio Grande do Sul, Brasil Potiguara Mendes Silveira Jr, Universidade Federal de Juiz de Fora, Brasil Regiane Regina Ribeiro, Universidade Federal do Paraná, Brasil Rogério Ferraraz, Universidade Anhembi Morumbi, Brasil Rose Melo Rocha, Escola Superior de Propaganda e Marketing, Brasil Rozinaldo Antonio Miani, Universidade Estadual de Londrina, Brasil Sérgio Luiz Gadini, Universidade Estadual de Ponta Grossa, Brasil Simone Maria Andrade Pereira de Sá, Universidade Federal Fluminense, Brasil Veneza Mayora Ronsini, Universidade Federal de Santa Maria, Brasil Walmir Albuquerque Barbosa, Universidade Federal do Amazonas, Brasil

\section{COMISSÃO EDITORIAL}

Cristiane Freitas Gutfreind

Pontifícia Universidade Católica do Rio Grande do Sul, Brasil

Irene Machado

Universidade de São Paulo, Brasil

\section{CONSULTORES AD HOC}

Claudia Peixoto de Moura, Pontificia Universidade Católica do Rio Grande do Sul, Brasil Francisco Rüdiger, Pontifícia Universidade Católica do Rio Grande do Sul, Brasil Juremir Machado da Silva, Pontifícia Universidade Católica do Rio Grande do Sul, Brasil Maria Aparecida Baccega, Universidade de São Paulo, Brasil

Roberto Tietzmann, Pontifícia Universidade Católica do Rio Grande do Sul, Brasil

\section{EQUIPE TÉCNICA}

ASSISTENTE EDITORIAL I Márcio Zanetti Negrini

REVISÃO DE TEXTOS I Press Revisão

EDITORAÇÃO ELETRÔNICA I Roka Estúdio

CONTATO I revistaecompos@gmail.com
COMPÓS I www.compos.org.br

Associação Nacional dos Programas de Pós-Graduação em Comunicação

Presidente

Edson Fernando Dalmonte

Programa de Pós-Graduação em Comunicação

e Cultura Contemporânea - UFBA

edsondalmonte@uol.com.br

Vice-presidente

Cristiane Freitas Gutfreind

Programa de Pós-Graduação em Comunicação Social - PUC-RS cristianefreitas@pucrs.br

Secretário-Geral

Rogério Ferraraz

Programa de Pós-Graduação em Comunicação

Universidade Anhembi Morumbi

rogerioferraraz@anhembimorumbi.edu.br 